\title{
Self-compassion as a mediator of the association between autistic traits and depressive/anxious symptomatology
}

John Galvin, Ph.D. ${ }^{1}$ * Abby Howes, MRes ${ }^{1}$, Bethany Mccarthy ${ }^{1}$, BSc, \& Gareth Richards, Ph.D. ${ }^{2,3}$

${ }^{1}$ Department of Psychology, Birmingham City University, UK

${ }^{2}$ School of Psychology, Faculty of Medical Sciences, Newcastle University, UK

${ }^{3}$ Autism Research Centre, Department of Psychiatry, University of Cambridge, UK

* Corresponding author address: Department of Psychology, Curzon Building, 4 Cardigan Street, Birmingham City University, Birmingham, B4 7BD; email: john.galvin@bcu.ac.uk

This paper has been accepted for publication in the journal Autism: International Journal of Research and Practice (acceptance: $22^{\text {nd }}$ September 2020). 


\begin{abstract}
Self-compassion refers to the extension of kindness to oneself when faced with inadequacies, shortcomings or failures. This study examined the mediating role of self-compassion in the relationship between autistic traits and depressive/anxious symptomatology in the general population. Participants included 164 university students (69 males, 95 females) ranging in age from 18 to 51 years $(M=23.16, S D=7.81)$. Participants completed the Autism Spectrum Quotient, the Self-Compassion Scale, and the Hospital Anxiety and Depression Scale. A series of multiple mediation analyses were conducted using the bootstrapping method, and it was found that Total Self-Compassion and the two subscales of Compassionate Self-Responding and Uncompassionate Self-Responding partially mediated the relationship between autistic traits and anxious/depressive symptoms. The indirect effect of self-compassion accounted for $41.9 \%$ of the variance in the relationship between autistic traits and depressive symptoms and $50 \%$ of the variance in the relationship between autistic traits and anxiety symptoms. It was also further found that the correlation between autistic traits and self-compassion was significantly stronger in males than females. Although preliminary, the current findings suggest that self-compassion could potentially serve as a target for clinical intervention in individuals with elevated autistic traits who experience anxiety and/or depression.
\end{abstract}

Keywords: Autistic traits; self-compassion; anxiety; depression; autistic spectrum conditions; autistic spectrum disorders. 


\section{Introduction}

Autism Spectrum Conditions (ASC) are a group of common heterogeneous neurodevelopmental conditions broadly characterised by social and communication difficulties in addition to restrictive and repetitive behaviours (American Psychiatric Association, 2013). We prefer the term ASC than ASD (Autism Spectrum Disorders), because "individuals with an ASC have not only disabilities which require a medical diagnosis, but also areas of cognitive strength" (Baron-Cohen et al., 2009, p. 500). Researchers commonly examine phenomena relevant to autism by measuring autistic traits, a set of primary symptoms associated with ASCs, which are normally distributed throughout the general population (Baron-Cohen et al., 2001; Ruzich et al., 2015).

Individuals in the general population without a diagnosis of ASC but with sub-clinical autistic traits show a constellation of cognitive and socio-communicative features that resemble ASC symptoms but that tend to be milder and less impairing, otherwise known as broader autism phenotypic traits (Piven et al., 1997). For these reasons, considerable research attention has focused on the relationships between autistic traits and cognitive and socio-communicative difficulties in samples without a clinical diagnosis of autism. Much of this research has considered how non-autistic people with subclinical autistic traits experience other peoples' feelings, emotions, and mental states, as well as how they respond to others in terms of sympathy, empathic interest, and compassion. For example, individuals who report high autistic traits in the general population typically show greater difficulties with social interaction (von dem Hagen \& Bright, 2019), emotion processing (Cooper et al., 2013), empathy (Zhao et al., 2018), and connecting with others (Stice \& Lavner, 2019). However, as autistic traits in non-autistic adults are also associated with social withdrawal (Churchard et al., 2019) and 
suicidal behaviour (Richards et al., 2019), it is important to not only consider how these individuals relate to others, but also how they relate to the self.

Self-compassion refers to the extension of kindness to oneself when faced with feelings of inadequacies, shortcomings, or failures (Neff, 2003). It comprises six diametrically opposite elements: three positive (self-kindness, common humanity and mindfulness) and three negative (self-judgement, isolation and over-identification). Self-kindness is the act of being supportive and caring towards the self in times of distress. The opposite of self-kindness is self-judgement, which occurs when an individual is hostile and critical towards aspects of their self during times of distress. Common humanity is a recognition that all people make mistakes and experience hard times throughout life, and that suffering and personal failure are part of a shared human experience. The opposite of common humanity is isolation, when an individual isolates their experiences and believes they are the only one facing hardship. Mindfulness is the state of awareness of, and ability to balance, negative thoughts and emotions in the present moment so that feelings are neither supressed nor exaggerated. Conversely, over-identification prevents the individual from experiencing the present moment by deliberating on their own limitations (Neff, 2003; Neff \& Vonk, 2009). The individual elements of self-compassion are said to interact with each other to generate a self-compassionate frame of mind (Neff \& Costigan, 2014), and research has supported the idea of a higher-order factor for selfcompassion (Neff et al., 2017; Cleare et al., 2018).

\subsection{The ongoing debate regarding the composition of self-compassion}

Neff et al. (2018) argued that the six elements of self-compassion are separable and do not covary in a lockstep manner, yet they do mutually impact one another and interact as a system. This includes a positive pole and a negative pole, with the positive elements of self-kindness, common humanity and mindfulness loading highly on one factor and the negative elements of 
self-judgement, isolation, and over-identification loading highly on the other. A considerable amount of research has supported the two-factor solution (e.g. Allen et al., 2020; Bengtsson et al., 2016; Stolow et al., 2016), and according to Neff (2016), the positive and negative aspects represent compassionate versus uncompassionate behaviours toward the self.

There is ongoing debate over whether self-compassion should be conceptualised and measured as an overarching construct, or if the compassionate versus uncompassionate dimensions should be considered distinct. Muris and Petrocchi (2017) suggested that the negative scales of self-compassion are problematic because they show stronger relationships with psychopathology and therefore inflate the link between self-compassion and wellbeing. However, Neff et al. (2018) argued that it is normal for measures to assess increased levels of positive and reduced levels of negative behaviours (e.g. healthy versus unhealthy food choices) and it is common to find that negative behaviours (as opposed to the absence of positive behaviours) have a stronger association with negative outcomes (Bonsaksen et al., 2018; GalilWeinstock et al., 2019). Indeed, an individual may not engage in vast amounts of compassionate behaviours towards themselves over any given period of time, but they may also not engage in a vast amount of uncompassionate ones either. Therefore, a lack of compassionate behaviours is not necessarily equal to increased uncompassionate behaviours, and vice versa.

\subsection{Sex differences in autistic traits and self-compassion}

A meta-analysis conducted by Ruzich et al. (2015) revealed that males typically report higher levels of autistic traits than females. This sex difference is congruent with the somewhat contested (e.g. Van Wijngaarden-Cremers et al., 2014; Schuck et al., 2019), albeit consistent, finding of a higher male to female ratio in people with diagnosed autism (Werling \& Geschwind, 2013). The higher prevalence of autistic traits in males could reflect a true 
difference between the sexes, a distinct phenotypic difference between males and females (Ferri et al., 2018), a systematic bias towards the typical presentation, diagnosis and measurement of autism (Jamison et al., 2017), or a combination of these factors.

Yarnell et al. (2015) conducted a meta-analysis focused on sex differences in self-compassion in the general population and found a small $(d=.18)$ but significant sex difference, with males reporting on average higher self-compassion than females. This is interesting because females tend to display greater empathic concern and compassion for others than do males (van der Graaf et al., 2014). However, this does not seem to translate to how females treat themselves. Indeed, females often prioritise the needs of others over their own (Yarnell et al., 2018), and ruminate over their problems more than males (Shors et al., 2017). Females diagnosed with autism and females undiagnosed but with sub-clinical autistic traits could be even more vulnerable to low self-compassion because, whereas autistic and sub-clinical males are more likely to show externalising behaviour (e.g. hyperactivity or problematic behaviours), autistic and sub-clinical females are more likely to internalise their problems (Mandy et al., 2012; Scherff et al., 2014; Bargiela et al., 2016). Taken together, these findings suggest that the association between autistic traits and self-compassion may operate slightly differently for males and females.

\subsection{Self-compassion as a mediator of the relationship between autistic traits and anxious/depressive symptoms}

To our knowledge, no research to date has considered the possible mediating role of selfcompassion in the relationship between autistic traits and anxious and depressive symptoms. This is surprising considering that low self-compassion is associated with higher levels of stress, anxiety and depression (Macbeth \& Gumley, 2012) and lower cognitive, affective and psychological wellbeing (Zessin et al., 2015). Emotion regulation styles, camouflaging, and 
alexithymia are also associated with autistic traits and psychopathology (Dworzynski et al., 2012; Morie et al., 2019) and can be further linked to self-compassion (Aydin et al., 2014; Rusk, 2015).

It is well documented that autistic people and non-autistic people with elevated autistic traits experience high levels of bullying (Bejerot \& Mortberg, 2009; Zablotsky et al., 2014) and are likely to experience non-acceptance from others (Cage et al., 2018; Cage et al., 2019; Sasson et al., 2017). Such experiences may increase the likelihood of camouflaging symptoms (Somerville et al., 2020), and vulnerability to self non-acceptance. Research in general population samples has found several possible mediators of the relationship between autistic traits and psychopathology, including social connectedness, loneliness, perceived burdensomeness (i.e. I am a burden), thwarted belonging (i.e. I am alone), social problemsolving ability, and teasing history (Pelton \& Cassidy, 2017; Rosbrook \& Whittingham, 2010; Stice \& Lavner, 2019).

It is possible that low self-compassion relates to certain aspects of a cognitive style akin to autism. For instance, particular facets of self-compassion (such as isolation over common humanity) could be associated with difficulties connecting with others, and a struggle for personal social readjustment. As autistic people often feel that their social difficulties mean others do not understand them (Bogdashina, 2016), this could lead to deliberation on perceived limitations (i.e. over-identification over mindfulness), and result in being hostile and critical towards aspects of their self (i.e. self-judgement over self-kindness). Furthermore, individuals with low self-compassion typically struggle to put their problems into perspective, are more likely to ruminate or supress negative emotions, and tend to demonstrate more extreme emotional reactions (Leary et al., 2007; Neff et al., 2007), all of which are positively correlated 
with autistic traits in autistic and non-autistic people (Brunye et al., 2012; Joshi et al., 2018; Zhao et al., 2020).

\subsection{Objective}

The current study explored relationships between autistic traits, self-compassion, and anxious/depressive symptoms in a non-clinical sample of undergraduate students. It was hypothesised that:

1) Autistic traits would be negatively associated with total self-compassion and the compassionate self-responding subscale, and positively associated with the uncompassionate self-responding subscale, and that all three associations would be evident in both males and females.

2) Total self-compassion, compassionate self-responding, and uncompassionate selfresponding would mediate the previously established positive association between autistic traits and anxious/depressive symptoms.

\section{Method}

Ethical approval was granted by the Department of Psychology at the host institution (PSY_Nov19_023) and participants provided informed consent before taking part. To determine the sample size required for a mediation analysis, an a priori power calculation was conducted using G*Power (Faul, Erfelder, Buchner \& Lang, 2014). Our sample size calculation was informed by the reported effect sizes from Rosbrook \& Whittingham (2010). With a medium effect size $\left(f^{2}\right)$ of .15 , an alpha of .05 , and a standard power level of .80 , this analysis determined that with the inclusion of one predictor variable (autistic traits) plus the mediators in the model (self-compassion total score, compassionate self-responding, and uncompassionate self-responding), a minimum of 85 participants would be required. 


\subsection{Participants}

The participants were 164 undergraduate university students (69 males, 95 females), mainly of White ethnicity $(87 \%)$, and ranging in age from 18 to 51 years $(M=23.16, S D=7.809)$. All were enrolled at a higher education institution in the West Midlands, UK. Some participants (30\% of the sample) were recruited through the Department of Psychology's Research Participation Scheme (RPS), in which psychology students participated for course credit. As scores on measures of autistic traits and self-compassion are on average higher in males than females (Ruzich et al., 2015; Yarnell et al., 2015), and the sex ratio is considerably female biased in undergraduate psychology students, we also aimed to recruit participants $(70 \%$ of the sample) by sharing details of the survey on the university social media page.

\subsection{Materials}

\subsubsection{Autism Spectrum Quotient}

The Autism Spectrum Quotient (AQ; Baron-Cohen et al., 2001) was administered to provide a quantitative measure of autistic traits. The AQ has commonly been used to investigate autistic traits in general population samples (Liu et al., 2016; Rosbrook \& Whittingham, 2010), including university students (Reed et al., 2016), and has proven to be a valid and reliable selfreport tool that is able to distinguish between those with and without an autism diagnosis (Baron-Cohen et al., 2001; Ruzich et al., 2015). It comprises 50 items that assess five trait subscales (social skill, attention switching, attention to detail, communication, and imagination), with the subscales being summed to provide an overall score (Baron-Cohen et al., 2001). The original authors suggested a score of $\geq 32$ indicated the likely presence of autism (Baron-Cohen et al.,2001), but scores $\geq 26$ are also considered clinically significant (Woodbury-Smith et al., 2005). Internal consistency (calculated from all individual items) for AQ total score in the current study was excellent, Cronbach's $\alpha=0.887$. 


\subsubsection{Self-Compassion Scale}

The Self-Compassion Scale (SCS; Neff, 2003) is a 26-item self-report questionnaire comprised of six subscales (self-kindness, self-judgement, common humanity, isolation, mindfulness and over-identification), with the overall self-compassion score calculated as the sum of the subscales (Neff, 2003). Compassionate and uncompassionate self-responding were also calculated by adding the relevant subscale scores: compassionate self-responding (sum score of self-kindness, common humanity, and mindfulness); uncompassionate self-responding (sum score of self-judgment, isolation, and over-identification). Internal consistency for total selfcompassion $(\alpha=0.933)$, compassionate self-responding $(\alpha=0.925)$, and uncompassionate selfresponding ( $\alpha=0.924)$ were each deemed to be excellent.

\subsubsection{Hospital Anxiety and Depression Scale}

The Hospital Anxiety and Depression Scale (HADS; Zigmond \& Snaith, 1983) consists of 14 items, seven measuring anxiety and seven measuring depressive symptoms. The questionnaire is designed to assess an individual's mental state over the previous two weeks, and is frequently used as a screening tool for anxiety and depression. The HADS was chosen for this study because it has been shown to be a reliable and valid tool in autistic and non-autistic populations (Bocerean \& Dupret, 2014; Uljarevic et al., 2019). A score of $\geq 11$ indicates the probable presence of a clinically meaningful anxiety or depressive condition. Internal consistency for the subscales used in the current study were as follows: anxiety symptoms, $\alpha=0.834$; depressive symptoms, $\alpha=0.830$.

\subsection{Procedure and Data Analysis}

Data were collected with an online self-report questionnaire hosted by Qualtrics and analysed using IBM SPSS version 25. We initially examined the associations between autistic traits and self-compassion in males and females using Pearson's correlation, and then compared the 
resulting slopes via Fisher's $r$ to $z$ transformation. The latter works by computing $z$ scores from the correlation coefficients and comparing these across the two analyses (Silver \& Dunlap, 1987). We then tested two mediation models with autistic traits (AQ total score) as predictor, self-compassion (SCS total score) as mediator, and depressive (HADS depression subscale) and anxious (HADS anxiety subscale) symptoms as outcomes. We further examined selfcompassion as a possible mediator of the association between autistic traits and anxious/depressive symptoms by focusing on specific indirect effects of compassionate and uncompassionate self-responding in a multiple mediation analysis. We used Preacher and Hayes' (2008) bootstrapping method to calculate the direct and indirect effects (Figure 1) and specified 5000 bootstrap resamples. To determine the statistical significance of the indirect effect, $95 \%$ confidence intervals (CI) were obtained. If the CIs do not contain zero, then the indirect effect is considered significant at the $p<.05$ level (Preacher \& Hayes, 2008).
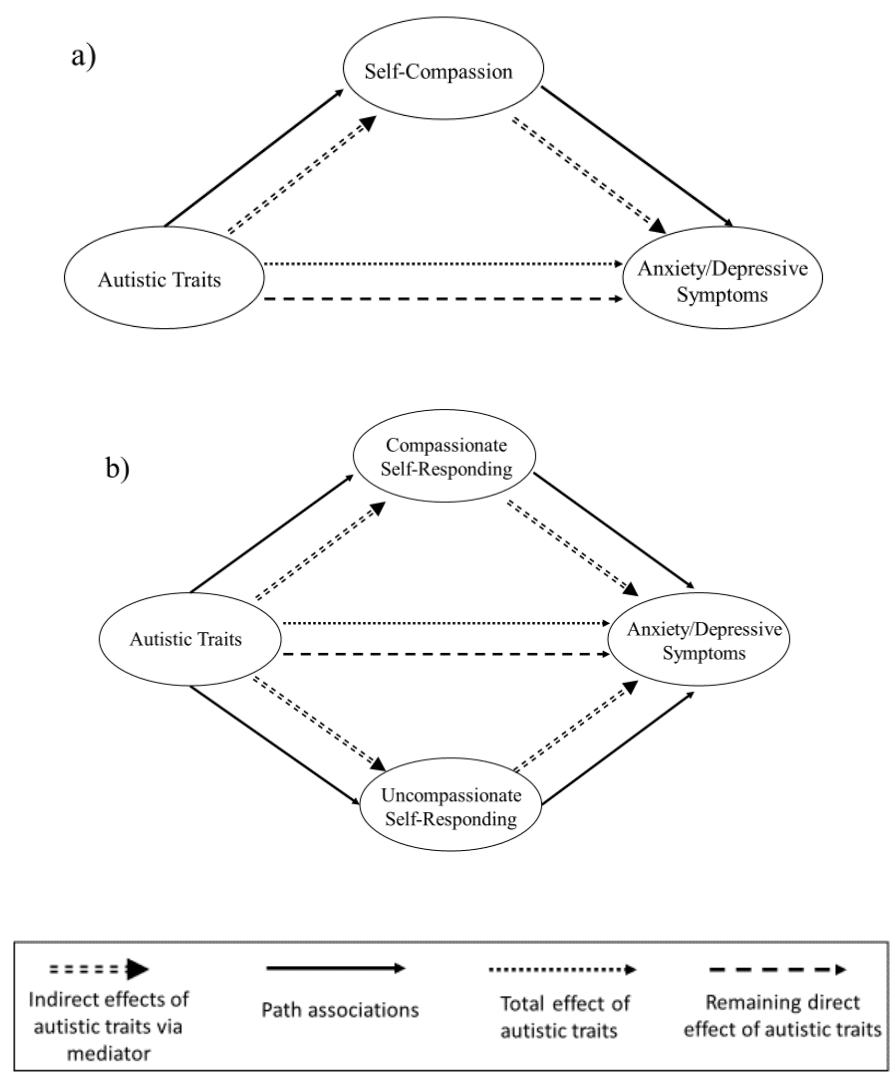

Figure 1. Mediation model of the effect of autistic traits on anxiety/depressive symptoms through a) total self-compassion and b) compassionate and uncompassionate self-responding 


\section{Results}

\subsection{Preliminary analyses}

Table 1 presents participant characteristics, including the means, standard deviations, and range for each study variable. An independent samples $t$-test revealed higher AQ scores in males ( $M$ $=21.36, S D=8.08)$ compared to females $(M=19.00, S D=6.84), t(162)=2.023, p=.045, d$ $=0.32$. However, there were no significant sex differences for depressive symptoms, anxiety symptoms, total self-compassion score, compassionate self-responding, uncompassionate selfresponding, or the six individual SCS subscales of self-kindness, self-judgement, common humanity, isolation, mindfulness, and over-identification.

\begin{tabular}{|c|c|c|c|}
\hline & $\begin{array}{l}\text { Males } \\
(\mathrm{n}=69)\end{array}$ & $\begin{array}{c}\text { Females } \\
(\mathbf{n}=95)\end{array}$ & $\begin{array}{l}\text { Total sample } \\
(\mathrm{N}=164)\end{array}$ \\
\hline \multicolumn{4}{|l|}{ Participant characteristics } \\
\hline$\overline{\text { Age } M, S D \text { (range) }}$ & $\begin{array}{l}22.50,7.18 \\
(18-31)\end{array}$ & $\begin{array}{l}23.64,8.23 \\
(18-51)\end{array}$ & $\begin{array}{l}23.16,7.81 \\
(18-51)\end{array}$ \\
\hline Ethnicity $n(\%)$ & $\begin{array}{c}\text { White }=60(87) \\
\text { Indian }=6(9) \\
\text { African=2(3) } \\
\text { Mixed } \\
\text { White/Asian=1(1) }\end{array}$ & $\begin{array}{c}\text { White }=82(86) \\
\text { Indian=8(9) } \\
\text { Pakistani=2(2) } \\
\text { Mixed } \\
\text { White/Asian=2(2) } \\
\text { Mixed White/Black } \\
\text { African=1(1) }\end{array}$ & $\begin{array}{c}\text { White=142(87) } \\
\text { Indian=14(9) } \\
\text { Mixed } \\
\text { White/Asian=3(2) } \\
\text { African=2(1) } \\
\text { Pakistani=2(1) } \\
\text { Mixed White/Black } \\
\text { African=1(1) }\end{array}$ \\
\hline Self-reported autism diagnosis $n(\%)$ & $0(0)$ & $1(1)$ & $1(1)$ \\
\hline $\begin{array}{l}\text { No current autism diagnosis, but the participant } \\
\text { suspects that they are autistic } n(\%)\end{array}$ & $1(1)$ & $2(2)$ & $3(2)$ \\
\hline AQ scores $\geq 26 n(\%)$ & $14(20)$ & $32(34)$ & $46(28)$ \\
\hline AQ scores $\geq 32 n(\%)$ & $7(10)$ & $2(2)$ & $9(5)$ \\
\hline Depressive symptoms $\geq 11 n(\%)$ & $34(49)$ & $34(36)$ & $68(41)$ \\
\hline Anxiety symptoms $\geq 11 n(\%)$ & $41(59)$ & $41(43)$ & $82(50)$ \\
\hline \multicolumn{4}{|l|}{ Study variables $M, S D($ range) } \\
\hline Total AQ score & $21.36,8.08(43.00)$ & $19.00,6.84(31.00)$ & $20.00,7.45(43.00)$ \\
\hline Total self-compassion score & $16.19,4.31(20.35)$ & $17.03,4.01(20.20)$ & $16.68,4.15(22.85)$ \\
\hline Compassionate self-responding & $8.77,2.52(10.65)$ & $9.07,2.34(11.80)$ & $8.94,2.42(11.80)$ \\
\hline Uncompassionate self-responding & $7.43,2.36(10.95)$ & $7.97,2.64(11.10)$ & $7.74,2.53(11.10)$ \\
\hline Self-kindness & $2.77,0.82(4.00)$ & $2.90,0.84(4.00)$ & $2.84,0.83(4.00)$ \\
\hline Self-judgement & $2.50,0.81(4.00)$ & $2.63,0.95(4.00)$ & $2.57,0.89(4.00)$ \\
\hline Common humanity & $3.00,0.99(4.00)$ & $3.06,0.94(4.00)$ & $3.04,0.96(4.00)$ \\
\hline Isolation & $2.50,0.89(4.00)$ & $2.67,0.98(4.00)$ & $2.60,0.95(4.00)$ \\
\hline Mindfulness & $3.00,0.90(4.00)$ & $3.11,0.85(4.00)$ & $3.01,0.87(4.00)$ \\
\hline Over-identification & $2.42,0.92(4.00)$ & $2.67,0.92(4.00)$ & $2.57,0.92(4.00)$ \\
\hline Anxiety symptoms & $10.99,4.62(21.00)$ & $10.24,4.77(21.00)$ & $10.54,4.71(21.00)$ \\
\hline Depressive symptoms & $10.25,2.92(16.00)$ & $9.67,2.95(16.00)$ & $9.91,2.94(17.00)$ \\
\hline
\end{tabular}

Table 1. Participant characteristics for the overall sample and stratified by sex 


\subsection{Association between autistic traits and self-compassion in males and females}

Hypothesis 1: Autistic traits will be negatively associated with total self-compassion and the compassionate self-responding subscale, and positively associated with the uncompassionate self-responding subscale, and all three associations would be evident in both males and females.

A Pearson's correlation test determined that total AQ score was significantly negatively correlated with total SCS score, $r(162)=-.458, p<.001)$. Furthermore, a Fisher's $r$-to- $z$ transformation determined that the correlation was significantly stronger in males $r(67)=-$ $.593, p<.001$, than females $r(93)=-.321 p=.002, z=-2.17 p=0.03$, two-tailed (Figure 2).

(a)

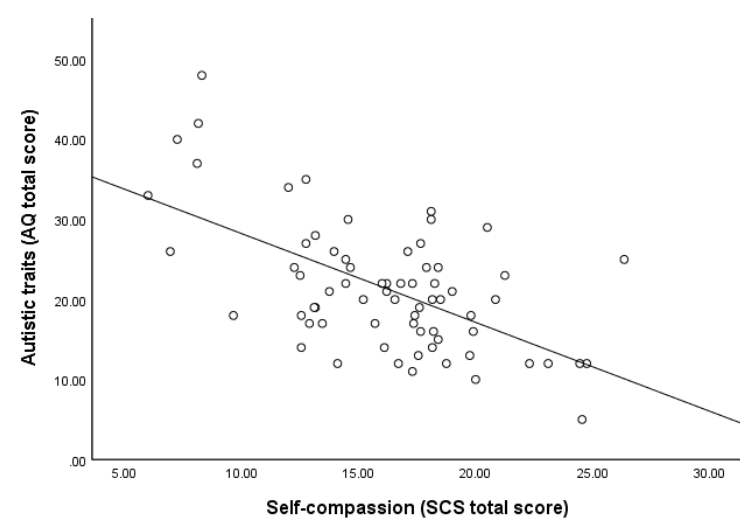

(b)

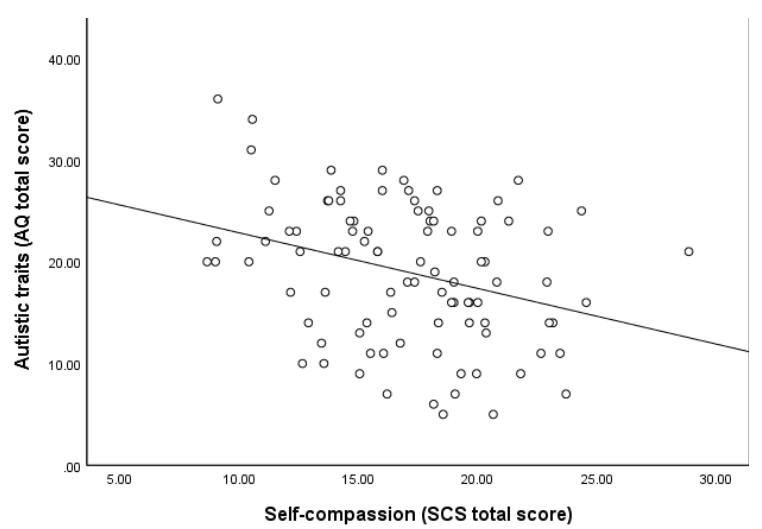

Figure 2. Association between AQ (total) and SCS (total) in males (a) and females (b)

Pearson's correlations for all scales are presented in Table 2. As predicted, total AQ score was negatively correlated with compassionate self-responding $(r(162)=-.433, p<.001)$, and positively associated with uncompassionate self-responding $(r(162)=.337, p<.001)$. To counteract the problem of multiple comparisons, the $p$ values reported in Table 2 are adjusted using Holm's procedure (Holm, 1979). 


\begin{tabular}{|c|c|c|c|c|c|c|c|c|c|c|c|}
\hline Variable & $\begin{array}{l}\text { Depressive } \\
\text { symptoms }\end{array}$ & $\begin{array}{l}\text { Anxiety } \\
\text { symptoms }\end{array}$ & $\begin{array}{l}\text { Total } \\
\text { AQ }\end{array}$ & $\begin{array}{l}\text { Total } \\
\text { SCS }\end{array}$ & $\begin{array}{l}\text { Self- } \\
\text { kindness }\end{array}$ & $\begin{array}{l}\text { Self- } \\
\text { judge } \\
\text { ment }\end{array}$ & $\begin{array}{l}\text { Common } \\
\text { humanity }\end{array}$ & Isolation & $\begin{array}{l}\text { Mindful } \\
\text { ness }\end{array}$ & $\begin{array}{l}\text { Over- } \\
\text { identification }\end{array}$ & $\begin{array}{l}\text { Compassion } \\
\text { ate self- } \\
\text { responding }\end{array}$ \\
\hline Anxiety & $.75 * *$ & & & & & & & & & & \\
\hline Total AQ & $48^{* *}$ & $.40 * *$ & & & & & & & & & \\
\hline Total SCS & $-.56^{* *}$ & $-.52 * *$ & $-.46^{* *}$ & & & & & & & & \\
\hline Self-kindness & $-.42 * *$ & $-.38^{*}$ & $-.36^{*}$ & $.78^{* *}$ & & & & & & & \\
\hline Self-judgement & $.43^{* *}$ & $.40^{* *}$ & $.27 *$ & $-.79 * *$ & $-.41 * *$ & & & & & & \\
\hline Common humanity & $-.42 * *$ & $-.40 * *$ & $-.42 * *$ & $.73 * *$ & $.70^{* *}$ & $-.32 *$ & & & & & \\
\hline Isolation & $.48^{* *}$ & $.42 * *$ & $.30^{*}$ & $-.78 * *$ & $-.40 * *$ & $.74 * *$ & $-.33^{*}$ & & & & \\
\hline Mindfulness & $-.39 *$ & $-.38^{*}$ & $-.40 * *$ & $.76^{* *}$ & $.79 * *$ & $-.33^{*}$ & $.75^{* *}$ & $-.32 *$ & & & \\
\hline Over-identification & $.42 * *$ & $.42 * *$ & $.36^{*}$ & $-.77 * *$ & $-.32 *$ & $.80^{* *}$ & $-.27 *$ & $.75^{* *}$ & $-.36^{*}$ & & \\
\hline $\begin{array}{l}\text { Compassionate self- } \\
\text { responding }\end{array}$ & $-.45 * *$ & $-.42 * *$ & $-.43 * *$ & $.83 * *$ & $.90^{* *}$ & $-.39 *$ & $.90 * *$ & $-.38^{*}$ & $.93 * *$ & $-.34 *$ & \\
\hline $\begin{array}{l}\text { Uncompassionate } \\
\text { self-responding }\end{array}$ & $.48^{* *}$ & $.45^{* *}$ & $.34 *$ & $-.85 * *$ & $-.41 * *$ & $.92 * *$ & $-.33 *$ & $.91 * *$ & $-.37 *$ & $.92 * *$ & $-.40 * *$ \\
\hline
\end{tabular}

Table 2. Means, standard deviations and intercorrelations for study variables

$$
* p<.05 * * p<.01
$$

Sex differences in the correlations between autistic traits and the individual self-compassion subscales were then examined (Table 3). A Fisher's $r$-to-z test determined that the slopes for the association between autistic traits and uncompassionate self-responding were significantly different between males and females, with a stronger association present in males. No significant sex difference was observed for the association between autistic traits and compassionate self-responding. When considering the six SCS subscales, a significantly stronger (negative) association was found in males compared to females for the association between autistic traits and self-kindness, as well as significantly stronger (positive) associations in males for all three negative scales (i.e. self-judgement, isolation, and over-identification).

\begin{tabular}{lccccccccc}
\hline & $\begin{array}{l}\text { Total } \\
\text { SCS }\end{array}$ & $\begin{array}{l}\text { Compassionate } \\
\text { self-responding }\end{array}$ & $\begin{array}{l}\text { Uncompassionate } \\
\text { self-responding }\end{array}$ & $\begin{array}{l}\text { Self- } \\
\text { kindness }\end{array}$ & $\begin{array}{l}\text { Self- } \\
\text { judgement }\end{array}$ & $\begin{array}{l}\text { Common } \\
\text { humanity }\end{array}$ & Isolation & $\begin{array}{l}\text { Mindful } \\
\text { ness }\end{array}$ & $\begin{array}{l}\text { Over- } \\
\text { identification }\end{array}$ \\
\hline Male Pearson's $\boldsymbol{r}$ & $-59^{* *}$ & $-515^{* *}$ & $.531^{* *}$ & $-.50^{* *}$ & $.50^{* *}$ & $-.48^{* *}$ & $.43^{* *}$ & $-.47^{* *}$ & $.51^{* *}$ \\
Female Pearson's $\boldsymbol{r}$ & $-.32^{* *}$ & $-.352^{* *}$ & $.175^{*}$ & $-.23^{* *}$ & .092 & $-.36^{* *}$ & $.19^{*}$ & $-.34^{* *}$ & $.20^{*}$ \\
Fisher's $\boldsymbol{r}$-to-z $(\mathbf{z})$ & $-2.15^{*}$ & 0.105 & $-2.571^{* *}$ & $-1.95^{*}$ & $2.85^{* *}$ & -0.91 & $1.67^{*}$ & -0.97 & $2.23^{*}$ \\
\hline
\end{tabular}

Table 3. Pearson's correlations and Fisher's r-to-z tests (two-tailed) for associations between autistic traits and self-compassion scales stratified by sex. ${ }^{*} p<.05 ; * * p<.01$ 


\subsection{Self-compassion as a mediator between autistic traits and depressive symptoms}

Hypothesis 2: Total self-compassion, compassionate self-responding and uncompassionate self-responding will mediate the previously established positive association between autistic traits and anxious/depressive symptoms.

The first mediation model $(\mathrm{N}=164)$ investigated self-compassion as a mediator between autistic traits and depressive symptoms. The overall model fit was significant $F(2,161)=$ $47.526, p<.001$, with an adjusted $R^{2}$ of .37 , indicating that $37 \%$ of the variance in depressive symptoms was predicted by autistic traits and self-compassion. As shown in Figure 3, the results for the indirect effect of autistic traits on depressive symptoms was statistically significant $(a b=.13,95 \%$ CI $[.0766, .1757])$, with $41.9 \%$ of the relationship between autistic traits and depressive symptoms being explained through the mediating effect of selfcompassion. However, there remained a direct effect of autistic traits on depressive symptoms independent of self-compassion $\left(c^{\prime}=.18, p=.001\right)$, suggesting partial mediation.

The second mediation model $(\mathrm{N}=164)$ investigated self-compassion as a potential mediating link between autistic traits and anxiety symptoms. This model was statistically significant $F(2$, $161)=35.244, p<.001$, adjusted $R^{2}=.31$, indicating that $31 \%$ of the variance in anxiety symptoms was predicted by variation in autistic traits and self-compassion. The indirect effect on anxiety symptoms was significant, $(a b=.14,95 \%$ CI $[.0829, .1981])$, with $50 \%$ of the relationship between autistic traits and anxiety being explained through self-compassion. The direct effect of autistic traits on anxiety symptoms was also significant, $\left(c^{\prime}=.14, p=.008\right)$, indicating partial mediation (Figure 3). 

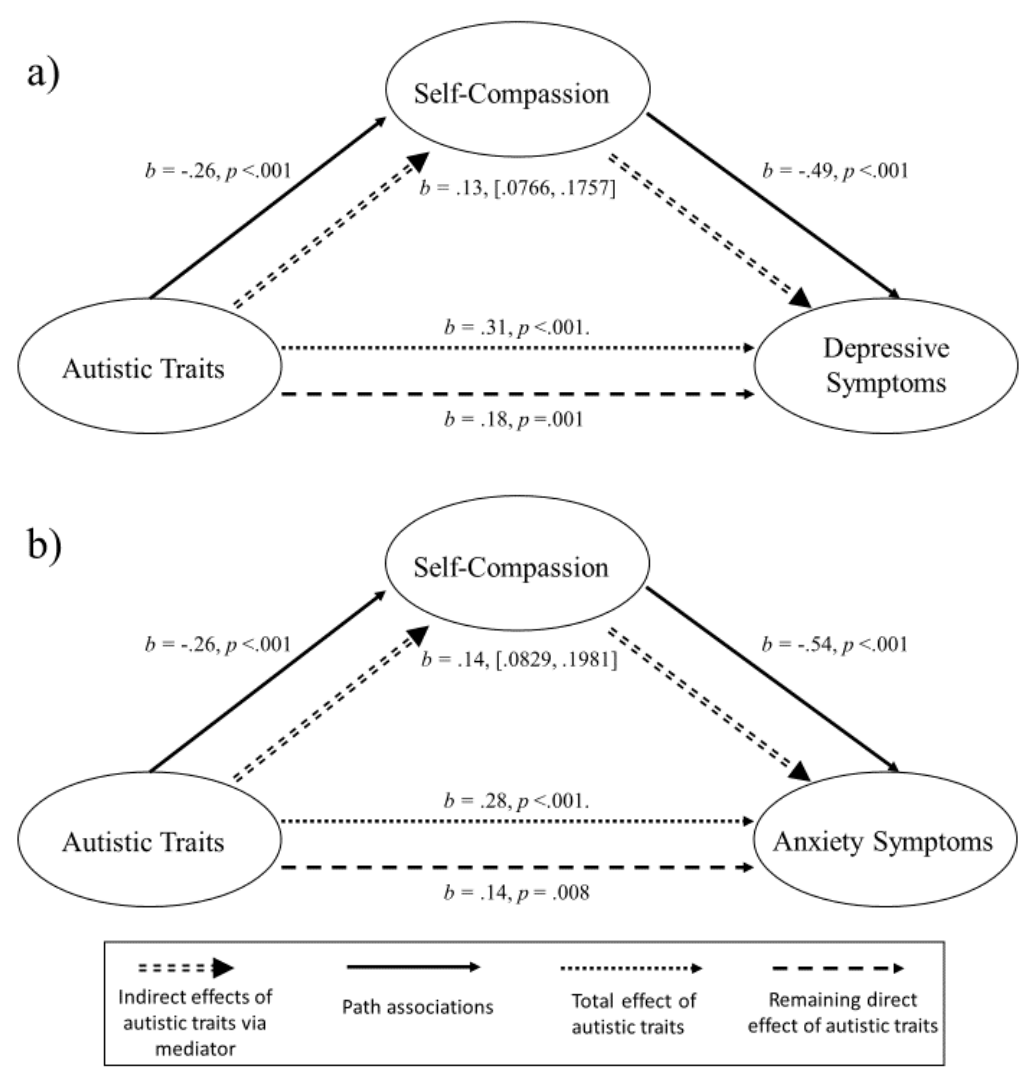

Figure 3. Partial mediation effect of self-compassion on the associations between autistic traits and a) depressive symptoms and b) anxiety symptoms

To assess the specific indirect effects of compassionate and uncompassionate self-responding we conducted two multiple mediation analyses (Figure 4). The first examined the relationship between autistic traits and depressive symptoms. The combined indirect effect of compassionate and uncompassionate self-responding was significant $F(3,160)=31.821, p<$ .001 , adjusted $R^{2}=.37$, and therefore indicated that the relationship was explained by the set of mediators as a whole. To determine whether either individual variable significantly mediated the association between AQ and depressive symptoms, the specific indirect effects were then examined. Significant indirect effects were observed for both compassionate $(a b=.06,95 \%$ CI $[.0074, .1083])$ and uncompassionate self-responding $(a b=.07,95 \%$ CI $[.0282, .1088])$. The second multiple mediation analysis examined the association between autistic traits and anxiety symptoms. A significant combined indirect effect of compassionate and 
uncompassionate self-responding was observed, $F(3,160)=23.522, p<.001$, adjusted $R^{2}=$ .31 , indicating that the relationship was explained by the set of mediators. Further analysis revealed significant indirect effects for both compassionate self-responding $(b=.06,95 \% C I$ $=.0138, .1241)$ and uncompassionate self-responding $(b=.07,95 \% C I=.0243, .1240)$.
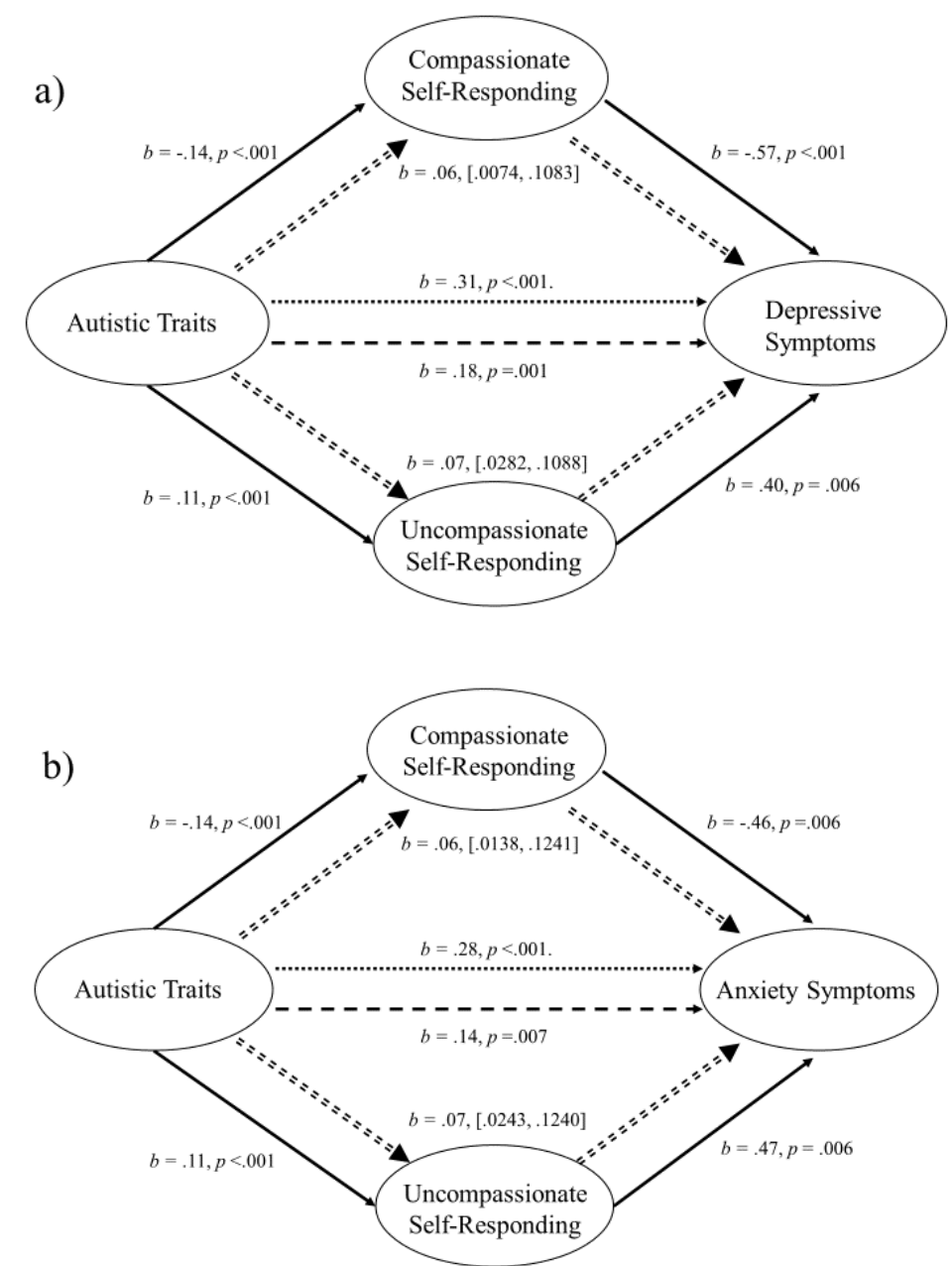

\begin{tabular}{|c|c|c|c|}
\hline$====\pi$ & & …................... & $----\longrightarrow$ \\
\hline $\begin{array}{l}\text { Indirect effects of } \\
\text { autistic traits via } \\
\text { mediator }\end{array}$ & Path associations & $\begin{array}{l}\text { Total effect of } \\
\text { autistic traits }\end{array}$ & $\begin{array}{l}\text { Remaining direct } \\
\text { effect of autistic traits }\end{array}$ \\
\hline
\end{tabular}

Figure 4. Mediation model of a) autistic traits and depressive symptoms and b) autistic traits and anxiety symptoms through compassionate and uncompassionate self-responding 


\section{Discussion}

To our knowledge, this is the first study to examine the mediating role of self-compassion on the relationship between autistic traits and anxious and depressive symptoms. The findings support our first hypothesis; autistic traits are negatively correlated with self-compassion and this relationship holds true for both males and females. We also found support for our second hypothesis: self-compassion is a partial mediator in the previously established positive relationship between autistic traits and anxiety/depressive symptoms. Although preliminary, the current findings suggest that self-compassion could potentially serve as a target for clinical intervention in individuals with elevated autistic traits who experience anxiety and/or depression.

The finding of a negative association between autistic traits and self-compassion suggests that individuals with elevated autistic traits may have limited self-compassion capabilities. This insight is relevant to clinicians working with anxious and/or depressed patients with elevated autistic traits, e.g. when providing psychoeducation to patients and families and/or when considering suitable treatment options. The mediation analyses revealed that the partially mediating role of self-compassion in the autistic traits and anxiety/depression pathway operates roughly equally through both compassionate and uncompassionate self-responding. This suggests a need to both increase compassionate self-responding and decrease uncompassionate self-responding when designing targeted interventions for reducing anxious/depressive symptoms in individuals with elevated autistic traits. Indeed, the inclination for clinicians working with such patients could be to focus on reducing the negative behaviours with which the patient presents (e.g. self-destructive behaviours), and this could inform discussions and treatment planning. This may additionally be true of the patient's family or significant others, who may also be focused on reducing or eradicating negative behaviours. 
The findings of this study suggest that an equivalent therapeutic benefit could be possible through a combined effort of increasing positive self-responding (i.e. increasing mindfulness, self-kindness and common humanity) and reducing negative self-responding (i.e. decreasing over-identification, self-judgement and isolation). For example, an unbalanced focus on the negative (what you are doing wrong and needs to be reduced) and not the positive (what can be increased to make you feel better) may cause further deliberation on perceived limitations (i.e. over-identification over mindfulness), increased self-criticality (i.e. self-judgement over self-kindness), and a reduced belief that we all make mistakes (i.e. isolation over common humanity). It may also influence other known mediators of the relation between autistic traits and psychopathological outcomes, such as reinforcing the belief that other people do not understand them, and increasing feelings of non-acceptance, perceived burdensomeness, and thwarted belonging, which, as previously mentioned, are all potential risk factors for anxiety, depression, and suicidality (Cage et al., 2018; Pelton \& Cassidy, 2017).

As a first step in the investigation of autistic traits, self-compassion, and anxious/depressive symptoms, it seemed appropriate to consider self-compassion as a unidimensional construct when investigating its association with autistic traits. This is why the current study considered self-compassion as a higher-order construct before examining it in terms of a more nuanced two-factor structure. Such an approach is strengthened by studies which show a simultaneous increase in the positive and decrease in the negative subscales of self-compassion (Halamova et al., 2019; Krieger et al., 2016). However, although some individuals (e.g. autistic people) may not exhibit the same theorised combinations of self-compassion components as found in our undergraduate student sample, the findings of the present study do support Neff's proposition that a self-compassionate frame of mind is an interactive and synergistic system that influences outcomes through both a positive and negative pole (Neff, 2016). 
Although we did not observe a significant sex difference in levels of self-compassion in our study, it was interesting that the strength of association between autistic traits and selfcompassion differed significantly between males and females. There are several reasons to expect a stronger association between AQ and SCS scores in males. Firstly, it could be that the observed differences are reflective of a systematic male bias in the measures used, and, as previously mentioned, this has been a target for criticism particularly in the autism literature (e.g. Van Wijngaarden-Cremers et al., 2014). However, it could equally be argued that the findings are indeed reflective of a sex difference in the associations between males and females on these measures. This is supported by research which found that correlations between selfcompassion and mental illness were stronger in males compared to females (Neff \& Pommier, 2013), as well as research showing that self-compassion had a greater protective effect on anxiety for males than for females (Bluth et al. 2017). The findings of our study are therefore reflective of a wider pattern of results in the literature, with sex differences being found in the associations between self-compassion and a range of psychopathological outcomes.

Further investigation is required to consider whether the sex difference observed in the general population (i.e. slightly higher on average self-compassion in males than females; Yarnell et al., 2015) also exists in autistic populations. Although speculative at this point, if this sex difference does exist, then self-compassion could be one mechanism, in part, which helps to explain earlier presentation and diagnosis of autism in males. For example, high selfcompassion involves a greater understanding, expression, and verbalisation of the challenges faced (Neff, 2003), as well as reductions in perceived public and anticipated stigma of seeking help (Heath et al., 2016). Self-compassion could therefore increase help seeking behaviours in autistic people and/or result in autistic symptomatology being more evident to social contacts (e.g. family, friends, teachers) and at an earlier stage of development for males compared to females. If the predicted associations between self-compassion and masking/help-seeking 
behaviours do indeed exist, this could suggest an important role for self-compassion interventions given the previously established associations between autistic traits, camouflaging/help-seeking, and anxiety, depression, and suicidality (e.g. Cassidy et al. 2019; Somerville et al., 2019).

Self-compassion is a relatively new area of research in psychology, spanning less than a couple of decades, and largely dominated by the Neff (2003) model thus far. As the area expands and more measures of self-compassion are developed, self-compassion in autistic populations can be better understood. Research suggests that autistic people may interpret measures/wording of questions differently than non-autistic people (Cassidy et al., 2018; Pelton et al., 2020), highlighting the need to investigate whether specific self-compassion measures will need to be developed for use with autistic populations. However, these concerns may be unfounded, as the SCS has shown to be a reliable and valid scale in clinical and non-clinical samples (e.g. Castilho et al., 2015; Neff, 2016), and a number of other psychological measures, including the AQ and the HADS, have shown to be suitable for use in both autistic and non-autistic populations (Baron-Cohen et al., 2001; Uljarevic et al., 2019). Either way, if the relationships observed in the present study between autistic traits, self-compassion, and psychopathology are also found in autistic people, future studies could then investigate the psychometric properties of the SCS to confirm if it is a reliable and valid measure for use in autistic samples.

A recent meta-analysis of available randomised controlled trials on self-compassion interventions showed significant improvements across a range of psychological outcomes, including stress, self-criticism, anxiety, and depression (Ferrari et al., 2019). However, no studies to date have specifically looked at self-compassion as a possible underlying mechanism in the treatment process for people with elevated autistic traits or people with a diagnosis of autism. Despite this, several mindfulness and acceptance-based intervention studies have 
supported the efficacy of compassion training in lessening anxious/depressive symptoms in autistic populations (e.g. Singh et al., 2011a; Singh et al., 2011b; Spek et al., 2013), suggesting that self-compassion could play a role in the treatment process. For example, Spek et al. (2013) found a significant reduction in anxiety, depression, and rumination in autistic adults following a 9-week mindfulness-based therapy. Furthermore, in non-autistic adults, simultaneous improvements in positive and negative aspects of self-compassion have been reported in a variety of interventions, including compassion focused therapy (Beaumont et al., 2016), acceptance and commitment therapy (Yadavaia et al., 2014), affect training (Hildebrandt et al., 2017), and mindfulness-based self-compassion training (Duarte \& Pinto-Gouveia, 2017).

Research on emotion differentiation has found that autistic and non-autistic individuals with elevated autistic traits make less subtle distinctions between negative emotions than do neurotypical individuals (Erbas et al., 2013; Huggins et al., 2019). Emotion differentiation refers to the ability to make fine-grained, nuanced distinctions between similar emotions, with lower emotion differentiation linked to poorer wellbeing (Smidt \& Suvak, 2015). A recent study of psychotherapy clients (Galil-Weinstock et al., 2019) showed that those with relatively high levels of self-compassion were better at distinguishing between negative (but not positive) emotional states, and a study conducted at a Stress Clinic in Belgium (Van der Gucht et al., 2019) reported that a mindfulness-based intervention led to a significant improvement in negative emotion differentiation at four-month follow-up.

Considering the above observations, it is possible that emotion differentiation moderates the self-compassion mediation pathway, i.e. a bi-directional relationship may exist in which selfcompassion training improves emotion differentiation and emotion differentiation improves the ability to be self-compassionate. Emotions are experienced by some individuals in a granular manner and described using discrete emotional terms (e.g., 'worried', 'afraid' or 
'upset'), whereas for other people emotions are more abstract and described in more general terms (e.g. 'good' and 'bad') (Galil-Weinstock et al., 2019). Therefore, individuals high in autistic traits who can identify and articulate their feelings with greater precision (e.g. 'I am not flustered, I am not embarrassed, but I am ashamed') will also have enhanced capabilities to reflect on, make sense of, and deal with, negative thoughts, feelings, and emotions. This can result in greater self-compassion, and, in clinically anxious/depressed individuals, could improve the clinician-patient relationship by allowing more productive and dynamic discussions around emotional experiences. Additionally, a study by Israelashvili et al. (2019) showed that improvements in emotion differentiation are also related to improved recognition of other peoples' emotions. A key point here is that self-compassion can be learned (Neff et al., 2018), and learning to be more self-compassionate enables people to be more self-aware, and better able to distinguish between their own and others' thoughts, feelings, and emotions. Future research should therefore investigate possible mechanisms that contribute to poor emotion differentiation in individuals with elevated autistic traits (e.g. differences in processing/perception, alexithymia, and/or cognitive inflexibility) and their possible links with self-compassion.

Given the high rates of anxiety and depression found in autistic people (Hollocks et al., 2019), future research should prioritise extending the current study to a clinical sample of autistic people. It should be noted that there are several unmeasured variables in the current study which could explain the relationships observed and are highly relevant to difficulties related to autism (e.g. sensory insensitivities or emotion regulation styles). Future research on autistic populations would therefore benefit from including these and additional measures to determine how self-compassion relates to other possible mediators between autistic traits and psychopathology. 
In addition to the need to investigate these relationships in autistic people, future research could also recruit samples from more divergent groups in the general population. Indeed, the metaanalysis by Yarnell et al. (2015) revealed that a larger sex difference in self-compassion is present in more ethnically diverse samples. Another important factor is age. Bluth et al. (2019), in a middle and high school student population $(\mathrm{N}=765)$, found that older females (high-school age) had lower self-compassion than younger females (middle-school age) and all-age males. This may therefore suggest that early intervention with females is important, as it could help protect against future anxiety that is mediated by the age-related decrease in self-compassion.

We had a relatively young sample (Mean age $=23.16$ years, $S D=7.809)$ taken from an undergraduate student population of predominantly White ethnicity. This limits generalisability of the findings to the wider population, and possibly to autistic individuals. However, as autism may be under-diagnosed in females (Rutherford et al., 2016; Giarelli et al., 2010), and females typically report higher rates of anxious/depressive disorders (Eid, Gobinath, \& Galea, 2019), this is a group at high risk for low self-compassion and poor mental health. Another limitation of the present research is its cross-sectional nature. Future research should adopt longitudinal designs before causality can be inferred in regard to the observed mediations found in this study.

Interestingly, the present study had a high percentage of participants who reached clinically relevant cut off scores on the AQ ( $\geq 26=28 \%$ ), as well as the HADS subscales (anxiety $=50 \%$, depression: $41 \%$ ). A potential explanation for this is that the institution from which our sample was drawn is a post-92 (old polytechnic) university which recruits a high proportion of students from low socio-economic backgrounds living in the poorest areas of the West Midlands, UK. This could explain why the scores are higher than other similar studies adopting these measures. For example, Pelton and Cassidy (2017) measured AQ in a student and general 
population sample and found that $16 \%$ reported clinically relevant AQ scores, and a study by Akram et al. (2020) administered the HADS to a sample of students in the UK and reported anxiety and depressive symptoms at $36 \%$ and $13 \%$, respectively. Furthermore, the AQ data from the present research is more in line with recent findings from a clinical sample of individuals experiencing a first episode of psychosis (Chisholm et al., 2019: $M=20.8$, cases $\geq 26=29 \%$ ). It could therefore be argued that the high scores reported in the current study may reduce generalisability to the general population and/or improve the generalisability to clinically anxious and/or depressed populations with elevated autistic traits.

\section{Conclusions and Implications}

Although preliminary, this study presents the first evidence that self-compassion mediates the previously established association between autistic traits and anxious/depressive symptoms in non-autistic adults. It provides a foundation for future work in this area and underlines the need for clinicians to be aware of how elevated autistic traits and low levels of self-compassion translate into anxiety and depressive symptomatology. A greater understanding of these relationships could improve treatment for anxious and depressive disorders in people with and without a diagnosis of autism.

\section{References}

Akram, U., Ypsilanti, A., McCarty, K., Lazuras, L., Gardani, M., Allen, S., \& Akram, A. (2019). The relationship between depression and insomnia symptoms amongst a sample of UK university students. Sleep Medicine Research, 10(1), 49-53. https://doi.org/10.17241/smr.2019.00332

Allen, L. M., Roberts, C., Zimmer-Gembeck, M. J., \& Farrell, L. J. (2020). Exploring the relationship between self-compassion and body dysmorphic symptoms in adolescents. Journal of Obsessive-Compulsive and Related Disorders, 25. https://doi.org/10.1016/j.jocrd.2020.100535 
American Psychiatric Association. (2013). Diagnostic and Statistical Manual of Mental Disorders (5th ed.). Author. https://doi.org/10.1176/appi.books.9780890425596

Aydin, A., Campus, G., \& Kadıköy, İ. T. (2014). An investigation of the relationship between selfcompassion, humor and alexithymic characteristics of parents with autistic children. International Journal on New Trends in Education and Their Implications, 5(2), 145-159.

Bargiela, S., Steward, R., \& Mandy, W. (2016). The Experiences of Late-diagnosed Women with Autism Spectrum Conditions: An Investigation of the Female Autism Phenotype. Journal of Autism and Developmental Disorders, 46(10), 3281-3294. https://doi.org/10.1007/s10803$016-2872-8$

Baron-Cohen, S., Scott, F. J., Allison, C., Williams, J., Bolton, P., Matthews, F. E., \& Brayne, C. (2009). Prevalence of autism-spectrum conditions: UK school-based population study. The British Journal of Psychiatry, 194(6), 500-509. https://doi.org/10.1192/bjp.bp.108.059345

Baron-Cohen, S., Wheelwright, S., Skinner, R., Martin, J., \& Clubley, E. (2001). The autism-spectrum quotient (AQ): evidence from Asperger syndrome/high-functioning autism, males and females, scientists and mathematicians. Journal of Autism and Developmental Disorders, 31(1), 5-17. https://doi.org/10.1023/a:1005653411471

Beaumont, E., Irons, C., Rayner, G., \& Dagnall, N. (2016). Does compassion-focused therapy training for health care educators and providers increase self-compassion and reduce self-persecution and self-criticism?. Journal of Continuing Education in the Health Professions, 36(1), 4-10. http://dx.doi.org/10.1097/CEH.0000000000000023

Bejerot, S., \& Mörtberg, E. (2009). Do autistic traits play a role in the bullying of obsessive-compulsive disorder and social phobia sufferers? Psychopathology, 42(3), 170-176. https://doi.org/10.1159/000207459

Bengtsson, H., Söderström, M., \& Terjestam, Y. (2016). The structure and development of dispositional compassion in early adolescence. The Journal of Early Adolescence, 36(6), 840873. https://doi.org/https://doi.org/10.1177/0272431615594461

Bluth, K., Campo, R. A., Futch, W. S., \& Gaylord, S. A. (2017). Age and Gender Differences in the Associations of Self-Compassion and Emotional Well-being in A Large Adolescent Sample. 
Journal of Youth and Adolescence, 46(4), 840-853. https://doi.org/10.1007/s10964-016-05672

Bocéréan, C., \& Dupret, E. (2014). A validation study of the Hospital Anxiety and Depression Scale (HADS) in a large sample of French employees. BMC psychiatry, 14(1), 354. https://doi.org/10.1186/s12888-014-0354-0

Bogdashina, O. (2016). Sensory perceptual issues in autism and asperger syndrome: different sensory experiences-different perceptual worlds. Jessica Kingsley Publishers.

Bonsaksen, T., Grimholt, T. K., Skogstad, L., Lerdal, A., Ekeberg, Ø., Heir, T., \& Schou-Bredal, I. (2018). Self-diagnosed depression in the Norwegian general population-associations with neuroticism, extraversion, optimism, and general self-efficacy. BMC Public Health, 18(1), 1076. https://doig.org/10.1186/s12889-018-5990-8

Brunyé, T. T., Ditman, T., Giles, G. E., Mahoney, C. R., Kessler, K., \& Taylor, H. A. (2012). Gender and autistic personality traits predict perspective-taking ability in typical adults. Personality and Individual Differences, 52(1), 84-88. https://doi.org/10.1016/j.paid.2011.09.004

Cage, E., Di Monaco, J., \& Newell, V. (2018). Experiences of autism acceptance and mental health in autistic adults. Journal of Autism and Developmental Disorders, 48(2), 473-484.

Cage, E., Di Monaco, J., \& Newell, V. (2019). Understanding, attitudes and dehumanisation towards autistic people. Autism, 23(6), 1373-1383. https://doi.org/10.1177/1362361318811290

Cassidy, S. A., Gould, K., Townsend, E., Pelton, M., Robertson, A. E., \& Rodgers, J. (2019). Is camouflaging autistic traits associated with suicidal thoughts and behaviours? Expanding the interpersonal psychological theory of suicide in an undergraduate student sample. Journal of Autism and Developmental Disorders, 1-11. https://doi.org/10.1007/s10803-019-04323-3

Cassidy, S. A., Bradley, L., Bowen, E., Wigham, S., \& Rodgers, J. (2018). Measurement properties of tools used to assess depression in adults with and without autism spectrum conditions: A systematic review. Autism Research, 11(5), 738-754. https://doi.org/10.1002/aur.1922 
Castilho, P., Pinto-Gouveia, J., \& Duarte, J. (2015). Evaluating the multifactor structure of the long and short versions of the self-compassion scale in a clinical sample. Journal of Clinical Psychology, 71(9), 856-870. https://doi.org/10.1002/jclp.22187

Churchard, A., Ryder, M., Greenhill, A., \& Mandy, W. (2019). The prevalence of autistic traits in a homeless population. Autism, 23(3), 665-676. https://doi.org/10.1177/1362361318768484

Cleare, S., Gumley, A., Cleare, C. J., \& O'Connor, R. C. (2018). An Investigation of the Factor Structure of the Self-Compassion Scale. Mindfulness, 9(2), 618-628. https://doi.org/10.1007/s12671-017-0803-1

Cooper, N. R., Simpson, A., Till, A., Simmons, K., \& Puzzo, I. (2013). Beta event-related desynchronization as an index of individual differences in processing human facial expression: further investigations of autistic traits in typically developing adults. Frontiers in Human Neuroscience, 7, 159. https://doi.org/10.3389/fnhum.2013.00159

Duarte, J., \& Pinto-Gouveia, J. (2017). Mindfulness, self-compassion and psychological inflexibility mediate the effects of a mindfulness-based intervention in a sample of oncology nurses. Journal of Contextual Behavioral Science, 6(2), 125-133. https://doi.org/10.1016/j.jcbs.2017.03.002

Dworzynski, K., Ronald, A., Bolton, P., \& Happe, F. (2012). How different are girls and boys above and below the diagnostic threshold for autism spectrum disorders? Journal of the American Academy of Child and Adolescent Psychiatry, 51(8), 788-797. https://doi.org/10.1016/j.jaac.2012.05.018

Eid, R. S., Gobinath, A. R., \& Galea, L. A. (2019). Sex differences in depression: Insights from clinical and preclinical studies. Progress in Neurobiology, 176, 86-102. https://doi.org/10.1016/j.pneurobio.2019.01.006

Erbas, Y., Ceulemans, E., Boonen, J., Noens, I., \& Kuppens, P. (2013). Emotion differentiation in autism spectrum disorder. Research in Autism Spectrum Disorders, 7(10), 1221-1227. https://doi.org/10.1016/j.rasd.2013.07.007 
Faul, F., Erdfelder, E., Lang, A. G., \& Buchner, A. (2007). G*Power 3: a flexible statistical power analysis program for the social, behavioral, and biomedical sciences. Behavior Research Methods, 39(2), 175-191. https://doi.org/10.3758/bf03193146

Ferrari, M., Hunt, C., Harrysunker, A., Abbott, M. J., Beath, A. P., \& Einstein, D. A. (2019). Selfcompassion interventions and psychosocial outcomes: A meta-analysis of RCTs. Mindfulness, 10(8), 1455-1473. https://doi.org/10.1007/s12671-019-01134-6

Ferri, S. L., Abel, T., \& Brodkin, E. S. (2018). Sex Differences in Autism Spectrum Disorder: a Review. Current Psychiatry Reports, 20(2), 9. https://doi.org/10.1007/s11920-018-0874-2

Galili-Weinstock, L., Lazarus, G., Atzil-Slonim, D., Bar-Kalifa, E., Rafaeli, E., \& Peri, T. (2019). Selfcompassion among psychotherapy clients is in the details of negative, not positive, emotions. The Journal of Positive Psychology, 1-10. https://doi.org/10.1080/17439760.2019.1627396

Giarelli, E., Wiggins, L. D., Rice, C. E., Levy, S. E., Kirby, R. S., Pinto-Martin, J., \& Mandell, D. (2010). Sex differences in the evaluation and diagnosis of autism spectrum disorders among children. Disability Health Journal, 3(2), 107-116. https://doi.org/10.1016/j.dhjo.2009.07.001

Halamová, J., Kanovský, M., Petrocchi, N., Moreira, H., López, A., Barnett, M. D., Eunjoo Yang, J. B., Brahler, E., Zeng, X., \& Zenger, M. (2020). Factor structure of the self-compassion scale in 11 international samples. Measurement and Evaluation in Counseling and Development, 123. https://doi.org/10.1080/07481756.2020.1735203

Heath, P. J., Brenner, R. E., Lannin, D. G., \& Vogel, D. L. (2018). Self-compassion moderates the relationship of perceived public and anticipated self-stigma of seeking help. Stigma and Health, 3(1), 65-68. https://doi.org/10.1037/sah0000072

Hildebrandt, L. K., McCall, C., \& Singer, T. (2017). Differential effects of attention-, compassion-, and socio-cognitively based mental practices on self-reports of mindfulness and compassion. Mindfulness, 8(6), 1488-1512. https://doi.org/10.1007/s12671-017-0716-Z

Hollocks, M. J., Lerh, J. W., Magiati, I., Meiser-Stedman, R., \& Brugha, T. S. (2019). Anxiety and depression in adults with autism spectrum disorder: A systematic review and meta-analysis. Psychological Medicine, 49(4), 559-572. https://doi.org/10.1017/s0033291718002283 
Huggins, C. F., Williams, J. H., \& Cameron, I. M. (2019). Different aspects of emotional awareness in relation to motor cognition and autism traits. Frontiers in Psychology, 10, 2439. https://doi.org/10.3389/fpsyg.2019.02439

Israelashvili, J., Oosterwijk, S., Sauter, D., \& Fischer, A. (2019). Knowing me, knowing you: emotion differentiation in oneself is associated with recognition of others' emotions. Cognition and Emotion, 33(7), 1461-1471. https://doi.org/10.1080/02699931.2019.1577221

Jamison, R., Bishop, S. L., Huerta, M., \& Halladay, A. K. (2017). The clinician perspective on sex differences in autism spectrum disorders. Autism, 21(6), 772-784. https://doi.org/10.1177/1362361316681481

Joshi, G., Wozniak, J., Fitzgerald, M., Faraone, S., Fried, R., Galdo, M., Furtak, S. L., Conroy, K., Kilcullen, J. R., Belser, A. \& Biederman, J. (2018). High risk for severe emotional dysregulation in psychiatrically referred youth with autism spectrum disorder: A controlled study. Journal of Autism and Developmental Disorders,48(9), 3101-3115. https://doi.org/10.1007/s10803-018-3542-9

Krieger, T., Martig, D. S., van den Brink, E., \& Berger, T. (2016). Working on self-compassion online: A proof of concept and feasibility study. Internet Interventions, 6, 64-70. https://doi.org/10.1016/j.invent.2016.10.001

Leary, M. R., Tate, E. B., Adams, C. E., Allen, A. B., \& Hancock, J. (2007). Self-compassion and reactions to unpleasant self-relevant events: the implications of treating oneself kindly. Journal of Personality and Social Psychology, 92(5), 887-904. https://doi.org/10.1037/00223514.92.5.887

Liu, J., Gong, J., Nie, G., He, Y., Xiao, B., Shen, Y., \& Luo, X. (2017). The mediating effects of childhood neglect on the association between schizotypal and autistic personality traits and depression in a non-clinical sample. BMC Psychiatry, 17(1), 352. https://doi.org/10.1186/s12888-017-1510-0

MacBeth, A., \& Gumley, A. (2012). Exploring compassion: a meta-analysis of the association between self-compassion and psychopathology. Clinical Psychology Review, 32(6), 545-552. https://doi.org/10.1016/j.cpr.2012.06.003 
Mandy, W., Chilvers, R., Chowdhury, U., Salter, G., Seigal, A., \& Skuse, D. (2012). Sex differences in autism spectrum disorder: evidence from a large sample of children and adolescents. Journal of Autism and Developmental Disorders, 42(7), 1304-1313. https://doi.org/10.1007/s10803011-1356-0

Morie, K. P., Jackson, S., Zhai, Z. W., Potenza, M. N., \& Dritschel, B. (2019). Mood Disorders in High-Functioning Autism: The Importance of Alexithymia and Emotional Regulation. Journal of Autism and Developmental Disorders, 49(7), 2935-2945. https://doi.org/10.1007/s10803019-04020-1

Muris, P., \& Petrocchi, N. (2017). Protection or vulnerability? A meta-analysis of the relations between the positive and negative components of self-compassion and psychopathology. Clinical Psychology \& Psychotherapy, 24(2), 373-383. https://doi.org/10.1002/cpp.2005

Neff, K. D. (2003). The Development and Validation of a Scale to Measure Self-Compassion. Self and Identity, 2(3), 223-250. https://doi.org/10.1080/15298860309027

Neff, K. D. (2016). The self-compassion scale is a valid and theoretically coherent measure of selfcompassion. Mindfulness, 7(1), 264-274. https://doi.org/10.1007/s12671-015-0479-3

Neff, K. D., \& Costigan, A. P. (2014). Self-compassion, wellbeing, and happiness. Psychologie in Österreich, 2(3), 114-119.

Neff, K. D., Kirkpatrick, K. L., \& Rude, S. S. (2007). Self-compassion and adaptive psychological functioning. Journal of Research in Personality, 41(1), 139-154. https://doi.org/10.1016/j.jrp.2006.03.004

Neff, K. D., Long, P., Knox, M. C., Davidson, O., Kuchar, A., Costigan, A., Williamson, Z., Rohleder, N., Toth-Kiraly, I., \& Breines, J. G. (2018). The forest and the trees: Examining the association of self-compassion and its positive and negative components with psychological functioning. Self and Identity, 17(6), 627-645. https://doi.org/10.1080/15298868.2018.1436587

Neff, K. D., \& Pommier, E. (2013). The relationship between self-compassion and other-focused concern among college undergraduates, community adults, and practicing meditators. Self and Identity, 12(2), 160-176. https://doi.org/10.1080/15298868.2011.649546 
Neff, K. D., \& Vonk, R. (2009). Self-compassion versus global self-esteem: two different ways of relating to oneself. Journal of Personality, 77(1), 23-50. https://doi.org/10.1111/j.14676494.2008.00537.x

Neff, K. D., Whittaker, T. A., \& Karl, A. (2017). Examining the Factor Structure of the SelfCompassion Scale in Four Distinct Populations: Is the Use of a Total Scale Score Justified? $\begin{array}{llll}\text { Journal of Personality } & \text { 596-607. }\end{array}$ https://doi.org/10.1080/00223891.2016.1269334

Pelton, M. K., \& Cassidy, S. A. (2017). Are autistic traits associated with suicidality? A test of the interpersonal-psychological theory of suicide in a non-clinical young adult sample. Autism Research, 10(11), 1891-1904. https://doi.org/10.1002/aur.1828

Pelton, M. K., Crawford, H., Robertson, A. E., Rodgers, J., Baron-Cohen, S., \& Cassidy, S. (2020). A Measurement Invariance Analysis of the Interpersonal Needs Questionnaire and Acquired Capability for Suicide Scale in Autistic and Non-Autistic Adults. Autism in Adulthood. https://doi.org/10.1089/aut.2019.0055

Piven, J., Palmer, P., Jacobi, D., Childress, D., \& Arndt, S. (1997). Broader autism phenotype: evidence from a family history study of multiple-incidence autism families. American Journal of Psychiatry, 154(2), 185-190.

Preacher, K. J., \& Hayes, A. F. (2008). Asymptotic and resampling strategies for assessing and comparing indirect effects in multiple mediator models. Behavior Research Methods, 40(3), 879-891. https://doi.org/10.3758/brm.40.3.879

Reed, P., Giles, A., Gavin, M., Carter, N., \& Osborne, L. A. (2016). Loneliness and Social Anxiety Mediate the Relationship between Autism Quotient and Quality of Life in University Students. Journal of Developmental and Physical Disabilities, 28(5), 723-733. https://doi.org/10.1007/s10882-016-9504-2

Richards, G., Kenny, R., Griffiths, S., Allison, C., Mosse, D., Holt, R., O'Connor, R. C., Cassidy, S., \& Baron-Cohen, S. (2019). Autistic traits in adults who have attempted suicide. Molecular Autism, 10, 26. https://doi.org/10.1186/s13229-019-0274-4 
Rosbrook, A., \& Whittingham, K. (2010). Autistic traits in the general population: What mediates the link with depressive and anxious symptomatology? Research in Autism Spectrum Disorders, 4(3), 415-424. https://doi.org/10.1016/j.rasd.2009.10.012

Rusk, D. A. (2015). Exploration of the relationship between self-compassion, alexithymia and emotion regulation in a clinical population. University of Edinburgh. http://hdl.handle.net/1842/11763

Rutherford, M., McKenzie, K., Johnson, T., Catchpole, C., O'Hare, A., McClure, I., Forsyth, K., McCartney, D., \& Murray, A. (2016). Gender ratio in a clinical population sample, age of diagnosis and duration of assessment in children and adults with autism spectrum disorder. Autism, 20(5), 628-634. https://doi.org/10.1177/1362361315617879

Ruzich, E., Allison, C., Smith, P., Watson, P., Auyeung, B., Ring, H., \& Baron-Cohen, S. (2015). Measuring autistic traits in the general population: a systematic review of the Autism-Spectrum Quotient (AQ) in a nonclinical population sample of 6,900 typical adult males and females. Molecular Autism, 6, 2. https://doi.org/10.1186/2040-2392-6-2

Sasson, N. J., Faso, D. J., Nugent, J., Lovell, S., Kennedy, D. P., \& Grossman, R. B. (2017). Neurotypical peers are less willing to interact with those with autism based on thin slice judgments. Scientific Reports, 7(1), 1-10. https://doi.org/10.1038/srep40700

Scherff, A., Taylor, M., Eley, T. C., Happé, F., Charman, T., \& Ronald, A. (2014). What causes internalising traits and autistic traits to co-occur in adolescence? A community-based twin study. Journal of Abnormal Child Psychology, 42(4), 601-610. https://doi.org/10.1007/s10802-013-9796-y

Schuck, R. K., Flores, R. E., \& Fung, L. K. (2019). Brief Report: Sex/gender differences in symptomology and camouflaging in adults with autism spectrum disorder. Journal of Autism and Developmental Disorders, 49(6), 2597-2604. https://doi.org/10.1007/s10803-019-03998$\mathrm{y}$

Shors, T. J., Millon, E. M., Chang, H. Y., Olson, R. L., \& Alderman, B. L. (2017). Do sex differences in rumination explain sex differences in depression? Journal of Neuroscience Research, 95(12), 711-718. https://doi.org/10.1002/jnr.23976 
Silver, N. C., \& Dunlap, W. P. (1987). Averaging correlation coefficients: Should Fisher's z transformation be used? Journal of Applied Psychology, 72(1), 146. https://doi.org/10.1037\%2F0021-9010.72.1.146

Singh, N. N., Lancioni, G. E., Manikam, R., Winton, A. S. W., Singh, A. N. A., Singh, J., \& Singh, A. D. A. (2011a). A mindfulness-based strategy for self-management of aggressive behavior in adolescents with autism. Research in Autism Spectrum Disorders, 5(3), 1153-1158. https://doi.org/10.1016/j.rasd.2010.12.012

Singh, N. N., Lancioni, G. E., Singh, A. D. A., Winton, A. S. W., Singh, A. N. A., \& Singh, J. (2011b). Adolescents with Asperger syndrome can use a mindfulness-based strategy to control their aggressive behavior. Research in Autism Spectrum Disorders, 5(3), 1103-1109. https://doi.org/10.1016/j.rasd.2010.12.006

Smidt, K. E., \& Suvak, M. K. (2015). A brief, but nuanced, review of emotional granularity and emotion differentiation research. Current Opinion in Psychology, 3, 48-51. https://doi.org/10.1016/j.copsyc.2015.02.007

Somerville, M., MacPherson, S. E., \& Fletcher-Watson, S. (2019). Camouflaging in non-autistic adults is associated with poorer mental health. https://doi.org/10.31234/osf.io/myp4g

Spek, A. A., van Ham, N. C., \& Nyklicek, I. (2013). Mindfulness-based therapy in adults with an autism spectrum disorder: a randomized controlled trial. Research in Developmental Disabilities, 34(1), 246-253. https://doi.org/10.1016/j.ridd.2012.08.009

Stice, L. V., \& Lavner, J. A. (2019). Social connectedness and loneliness mediate the association between autistic traits and internalizing symptoms among young adults. Journal of Autism and Developmental Disorders, 49(3), 1096-1110. https://doi.org/10.1007/s10803-018-3812-6

Stolow, D., Zuroff, D. C., Young, J. F., Karlin, R. A., \& Abela, J. R. Z. (2016). A Prospective Examination of Self-Compassion as a Predictor of Depressive Symptoms in Children and Adolescents. Journal of Social and Clinical Psychology, 35(1), 1-20. https://doi.org/10.1521/jscp.2016.35.1.1

Uljarević, M., Richdale, A. L., McConachie, H., Hedley, D., Cai, R. Y., Merrick, H., ... \& Le Couteur, A. (2018). The hospital anxiety and depression scale: Factor structure and psychometric 
properties in older adolescents and young adults with autism spectrum disorder. Autism Research, 11(2), 258-269. https://doi.org/10.1002/aur.1872

Van der Graaff, J., Branje, S., De Wied, M., Hawk, S., Van Lier, P., \& Meeus, W. (2014). Perspective taking and empathic concern in adolescence: gender differences in developmental changes. Developmental Psychology, 50(3), 881-888. https://doi.org/10.1037/a0034325

Van der Gucht, K., Dejonckheere, E., Erbas, Y., Takano, K., Vandemoortele, M., Maex, E., Raes, F., \& Kuppens, P. (2019). An experience sampling study examining the potential impact of a mindfulness-based intervention on emotion differentiation. Emotion, 19(1), 123-131. https://doi.org/10.1037/emo0000406

Van Wijngaarden-Cremers, P. J., van Eeten, E., Groen, W. B., Van Deurzen, P. A., Oosterling, I. J., \& Van der Gaag, R. J. (2014). Gender and age differences in the core triad of impairments in autism spectrum disorders: a systematic review and meta-analysis. Journal of Autism and Developmental Disorders, 44(3), 627-635. https://doi.org/10.1007/s10803-013-1913-9

von dem Hagen, E. A., \& Bright, N. (2017). High autistic trait individuals do not modulate gaze behaviour in response to social presence but look away more when actively engaged in an interaction. Autism Research, 10(2), 359-368. https://doi.org/10.1002/aur.1666

Werling, D. M., \& Geschwind, D. H. (2013). Sex differences in autism spectrum disorders. Current Opinion in Neurology, 26(2), 146-153. https://doi.org/10.1097/WCO.0b013e32835ee548

Woodbury-Smith, M. R., Robinson, J., Wheelwright, S., \& Baron-Cohen, S. (2005). Screening adults for Asperger syndrome using the AQ: A preliminary study of its diagnostic validity in clinical practice. Journal of Autism and Developmental Disorders,35(3), 331-335. https://doi.org/10.1007/s10803-005-3300-7

Yadavaia, J. E., Hayes, S. C., \& Vilardaga, R. (2014). Using acceptance and commitment therapy to increase self-compassion: A randomized controlled trial. Journal of Contextual Behavioral Science, 3(4), 248-257. https://doi.org/10.1016/j.jcbs.2014.09.002

Yarnell, L. M., Neff, K. D., Davidson, O. A., \& Mullarkey, M. (2018). Gender Differences in SelfCompassion: Examining the Role of Gender Role Orientation. Mindfulness, 10(6), 1136-1152. https://doi.org/10.1007/s12671-018-1066-1 
Yarnell, L. M., Stafford, R. E., Neff, K. D., Reilly, E. D., Knox, M. C., \& Mullarkey, M. (2015). MetaAnalysis of Gender Differences in Self-Compassion. Self and Identity, 14(5), 499-520. https://doi.org/10.1080/15298868.2015.1029966

Zablotsky, B., Bradshaw, C. P., Anderson, C. M., \& Law, P. (2014). Risk factors for bullying among $\begin{array}{llll}\text { children } \quad \text { with } & \text { autism } & \text { spectrum } & \text { disorders. Autism, 18(4), }\end{array}$ https://doi.org/10.1177/1362361313477920

Zessin, U., Dickhauser, O., \& Garbade, S. (2015). The Relationship Between Self-Compassion and Well-Being: A Meta-Analysis. Applied Psychology: Health and Well Being, 7(3), 340-364. https://doi.org/10.1111/aphw.12051

Zhao, X., Li, X., Song, Y., \& Shi, W. (2019). Autistic Traits and Prosocial Behaviour in the General Population: Test of the Mediating Effects of Trait Empathy and State Empathic Concern. Journal of Autism and Developmental Disorders, 49(10), 3925-3938. https://doi.org/10.1007/s10803-018-3745-0

Zhao, X., Li, X., Song, Y., Li, C., \& Shi, W. (2020). Autistic traits and emotional experiences in Chinese college students: Mediating role of emotional regulation and sex differences. Research in Autism Spectrum Disorders, 77, 101607. https://doi.org/10.1016/j.rasd.2020.101607

Zigmond, A. S., \& Snaith, R. P. (1983). The hospital anxiety and depression scale. Acta Psychiatrica Scandinavica, 67(6), 361-370. https://doi.org/10.1111/j.1600-0447.1983.tb09716.x 